Original

Article

\title{
Primary gastrointestinal non Hodgkin's lymphoma chemotherapy alone an effective treatment modality: Experience from a single centre in India
}

\author{
Raina Vinod, Sharma Atul, Vora Amish, Shukla NK*, Deo SVS*, Dawar $\mathbf{R}^{\star \star}$ \\ Departments of Medical Oncology, *Surgical Oncology and ${ }^{* *}$ Pathology, Institute Rotary Cancer \\ Hospital, All India Institute of Medical Sciences, New Delhi, India
}

Correspondence to: Atul Sharma, E-mail: atul1@hotmail.com

\section{Abstract}

BACKGROUND: Gastrointestinal tract (GI) is the most frequently involved extra nodal site in non-Hodgkin's lymphoma $(\mathrm{NHL})$. Surgery, radiotherapy and chemotherapy (CT) have been used mostly in various combinations, but lately chemotherapy alone has emerged as an effective option. The purpose of this study is to evaluate efficacy of CT alone in treatment of primary GI-NHL and to compare the results with combined CT + surgery. SETTING AND DESIGN: Retrospective analysis of case records of GI NHL patients. MATERIALS AND METHODS: Over a 15-year period (1986-2000), 77 new cases of primary GI-NHL were registered at our center. GI-NHL was defined according to standard criteria. All patients received chemotherapy. RESULTS: The median age was 32 years (Range 9-80). Endoscopy / CT guided biopsies were performed in $42 \%$ (32) of patients for the purpose of diagnosis. Laparotomy was done in $58 \%$ (45) of patients to establish a diagnosis or as primary or debulking treatment. Stomach and intestines were involved in 47\% (36) and 53\% (41) patients respectively. Early stage disease was present in 37\% (29). Seventy eight percent of tumors were intermediate to high grade, 43\% (33) received only CT while 57\% (44) received CT + surgery. Five years EFS and OS were: $72 \%$ and $65 \%$ for all patients; $72 \%$ and $67 \%$ for CT only group; $60 \%$ and $64 \%$ for $C T$ + surgery group $(P=0.05)$. Four patients died of neutropenic infection. CONCLUSION: Organpreservation strategy using chemotherapy alone (CT) can be successfully employed in a significant number of patients with primary GI-NHL.

Key Words: Primary non-Hodgkin's lymphoma of gastrointestinal tract, chemotherapy.

\section{Introduction}

The incidence of non-Hodgkin's lymphoma (NHL) has been increasing over the last three decades. During the same period an increase in incidence of extra nodal NHL has also been noted. ${ }^{[1]}$ Gastrointestinal tract represents the most frequent extra nodal site and it accounts for $4 \%$ of all gastrointestinal malignancies.

Although many large series of primary GI-NHL describing patterns of presentation and outcome have been published the consensus over the ideal treatment for GI-NHL still remains the subject of debate. ${ }^{[2-10]}$ Interpretation of the outcome data of these studies is hampered by differences in case selection, staging system, pathological classification and therapy. Surgery, radiotherapy (RT) and chemotherapy (CT) have all been used either alone or in combinations. Superiority of either single or combined modality over each others is still not proven. Surgery has traditionally remained the treatment of choice and chemotherapy is often used after surgery. Adjuvant radiotherapy is also practiced in some cases. Nevertheless surgery and radiotherapy are not without significant morbidity. NHL being a highly 
chemo sensitive disease it is now highly questionable whether radical or mutilating surgery is still necessary.

Advances in endoscopic techniques for obtaining tissue diagnosis, refinements in radiological methods such as CT scans and guided biopsies and efficacy of chemotherapy have created a new option in the treatment of GI-NHL. Chemotherapy has the advantage of organ preservation; in addition it is effective for micro-metastases and hence takes care of systemic disease. In the older studies of high grade GI-NHL, chemotherapy was employed either as an adjunct to surgery or in combination with radiotherapy. However more recent studies suggests that chemotherapy alone may be as effective particularly in primary gastric lymphomas. ${ }^{[11-13]}$

\section{Materials and Methods}

In this study we have analyzed 77 patients of primary GI-NHL treated at our center over the last 15 years (1986-2000). This review includes clinical features, histopathological classification, site of involvement, treatment outcome and prognostic factors. Some of our patients were operated in other hospitals before being referred to us. This gave us the opportunity to compare surgery + CT vs. CT alone group. Primary GI NHL was defined according to Lewin et al i.e. patients had to present with GI symptoms or have predominant lesions in the GI tract. ${ }^{[14]}$

The initial evaluation of all patients included a complete history and physical examination, complete blood count, liver and renal function tests, chest X-ray and computed tomographic scans. All patients where primary surgery was not performed underwent upper gastrointestinal endoscopic or colonoscopic studies or guided biopsies for obtaining tissue diagnosis. Bone marrow aspiration and biopsy was done in all patients. Patients were staged according to the Ann-Arbor classification as modified by Musshoff. ${ }^{[15]}$

The histopathology specimens of all patients were reviewed and classified according to the International Working Formulation, which was the classification followed in our institute during study period. ${ }^{[16]}$

All patients, irrespective of stage were administered chemotherapy. For patients with diffuse large B cell lymphoma and lymphoma of indeterminate histology, six cycles of CHOP (Cyclophosphamide $750 \mathrm{mg} / \mathrm{m}^{2}$, doxorubicin $50 \mathrm{mg} / \mathrm{m}^{2}$, Vincristine $1.4 \mathrm{mg} / \mathrm{m}^{2}$ with maximum of $2 \mathrm{mg}$, prednisolone 100mg for 5 days every 21 days) were given. For Burkitt's lymphoma, eight cycles of dose intensive MCP 842 was administered. ${ }^{[17]}$ All patients who were operated outside were also given chemotherapy as above.

Response criteria and end points were reported according to published guidelines. ${ }^{[18]}$ Re-evaluation after completion of treatment included endoscopy, CT-scans and complete blood count and biochemistry in addition to clinical examination. Patients were examined every three months for one year and six monthly thereafter.

\section{Statistical analysis}

The date of analysis was July 1, 2002. Event free survival (EFS) was determined from the time patients entered into complete or partial remission until recurrence or death from any cause, overall survival (OS) as time from diagnosis until death from any cause or till the last follow up. Patients in remission or alive were censored at the last known date of follow up evaluation. OS and EFS were calculated using Kaplan Meier method. For univariate analysis, log-rank test was performed using SPSS 10.0 version.

\section{Results}

The clinical features and patient characteristics are given in [Table 1]. Pain was the commonest symptom (81\%64 patients); fever and weight loss were the other frequent symptoms, either of them being present in $54.5 \%$ (43) of patients. Forty eight percent of patients presented with nausea, vomiting, constipation associated with abdominal pain. Only 3\% of patients presented with either hemetemesis or malena. Seventy eight percent (60) of patients had either intermediate or high grade NHL, none of our patients had low grade NHL. Four patients had Burkitt's lymphoma. Seventeen patients $(22 \%)$ could not be classified further into intermediate or high grade, as slides available were not of good quality. Stage wise, 16.8\% (13) and 20.7\% (16) of patients had early disease (i.e. stage I and stage

Table 1: Clinical features and patient characteristics

\begin{tabular}{ll}
\hline Median age (range in years) & $32(9-80)$ \\
\hline Male to female ratio & $2.2: 1$ \\
\hline Clinical features & \\
\hline - B- Symptoms present & $43(54.5 \%)$ \\
\hline - Median duration of symptoms & 3 months \\
\hline - Pain & $64(81 \%)$ \\
\hline - Hemetemesis & $2(2.5 \%)$ \\
\hline - Malena & $3(3 \%)$ \\
\hline - Subacute intestinal obstruction & $38(48.1 \%)$ \\
\hline
\end{tabular}


$\mathrm{II}_{1}$ respectively), while $37.6 \%$ and $15.5 \%$ had disseminated disease i.e. stage II 2 and stage IV respectively. Seven (9\%) patients could not be staged in the absence of the complete information.

The diagnosis of lymphoma was established by endoscopy in 25(30.4\%) patients, by USG/ CT guided biopsy techniques in $7(8.9 \%)$ patients. Diagnostic laparotomy was performed in $45(58.8 \%)$ patients. As shown in [Table 2], ulceroproliferative type of growth was seen in $(45.4 \%)$ patients. Nodular, infiltrative and polypoidal pattern was seen in $14.2 \%$ and $9 \%$ of patients respectively and mixed pattern was noted in $16.8 \%$ of patients. Stomach was the most common organ involved $(46.7 \%-36)$ as shown in [Figure 1]. Median age for small intestine NHL was much lower (30 years) compared to stomach and large intestinal NHL. B symptoms and abdominal pain was present in the majority of patients irrespective of site of involvement. There was equal distribution of patients as far as histology type of lesion and stage were concerned. Clinical features, histology, stage and site distribution has been shown in [Table 3].

The median follow up of the cohort was 72 months (range 0 to 112 months). Main side effects of chemotherapy were myelosuppression, vomiting and diarrhoea. No patient had perforation or hemorrhage following chemotherapy. Four patients died of neutropenic fever. The OS and EFS of the patients with primary GI-NHL were $65 \%$ and $72 \%$ respectively [Figures 2 and 3]. We had three groups of patients depending on the treatment they received; 1. Surgery (complete resection) + chemotherapy, 2. Surgery (partial resection) + chemotherapy, 3. Only chemotherapy. Survival of different treatment has been

\begin{tabular}{lc}
\hline Table 2: Type of lesion & $\mathrm{N}=77(\%)$ \\
\hline Type of lesion & $35(45.4)$ \\
\hline Ulceroproliferative & $11(14.2)$ \\
\hline Nodular & $11(14.2)$ \\
\hline Infiltrative & $07(9)$ \\
\hline Polypoidal & $13(16.8)$ \\
\hline Mixed
\end{tabular}

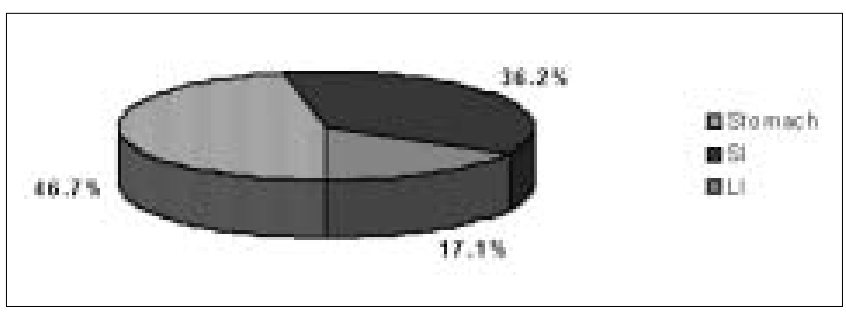

Figure 1: Shows distribution of GI-lymphoma according to site involved
Table 3: Shows clinical features, histology type of lesion and stage wise distribution in GIlymphoma according to the site involved

\begin{tabular}{|c|c|c|c|}
\hline Features & Stomach & SI & L. Intestine \\
\hline - Number & 36 (46.7) & $28(36.3)$ & 13 (17) \\
\hline - B-symptoms & $22(61)$ & $16(57.1)$ & $5(38.5)$ \\
\hline \multicolumn{4}{|l|}{ Histology } \\
\hline Intermediate grade & $14(38.8)$ & $12(42.8)$ & $5(38.5)$ \\
\hline High grade & $10(27.8)$ & $10(35.1)$ & $2(15.4)$ \\
\hline Mixed & - & $1(3.6)$ & $2(15.4)$ \\
\hline Burkitt's & $2(5.6)$ & $2(7.1)$ & - \\
\hline Unclassified & $10(27.8)$ & $3(10.7)$ & $4(30.8)$ \\
\hline \multicolumn{4}{|l|}{ Stage wise* } \\
\hline Stage I & $7(19.4)$ & $5(17.9)$ & $1(7.7)$ \\
\hline Stage $\|_{1}$ & $9(25)$ & $5(17.9)$ & $2(15.4)$ \\
\hline Stage $\mathrm{II}_{2}$ & $11(30.6)$ & $11(39.3)$ & $7(53.8)$ \\
\hline Stage IV & $6(16.7)$ & $5(17.9)$ & $1(7.7)$ \\
\hline \multicolumn{4}{|l|}{ Resection } \\
\hline Complete & $6(16.7)$ & $9(32.1)$ & $6(46.2)$ \\
\hline Incomplete & $9(25)$ & $11(39.3)$ & $3(23.1)$ \\
\hline No surgery & $21(58.3)$ & $8(28)$ & $4(30.8)$ \\
\hline
\end{tabular}

Figurss in the parenthesis are in percentage

shown in Table 4. A total of 23 deaths were recorded during the study period. Eight patients died of disease progression after relapse, four of neutropenic infection, nine patients did not achieve CR and died, two died in CR due to causes unrelated to the disease. Patients who did not achieve CR were treated with salvage protocols like IMVP-16 (Ifosfamide, Methotrexate and VP-16) or MINE (Mitoxanterone, Ifosfamide and VP -16).

\section{Prognostic variables}

We analyzed prognostic factors using univariate and multivariate analysis. We did not find any correlation between B symptoms, age, sex, stage, histopathological grade, site of involvement and survival. Patient who received chemotherapy alone had 5 year survival of $67 \%$ compared to $60-64 \%$ in group who had surgery and chemotherapy $(P=0.05)$.

\section{Discussion}

Primary GI-NHL represents a heterogeneous disease with regard to various characteristics like stage, site of involvement, histological subtypes and treatment offered. The commonest presenting symptom in GI-NHL is 


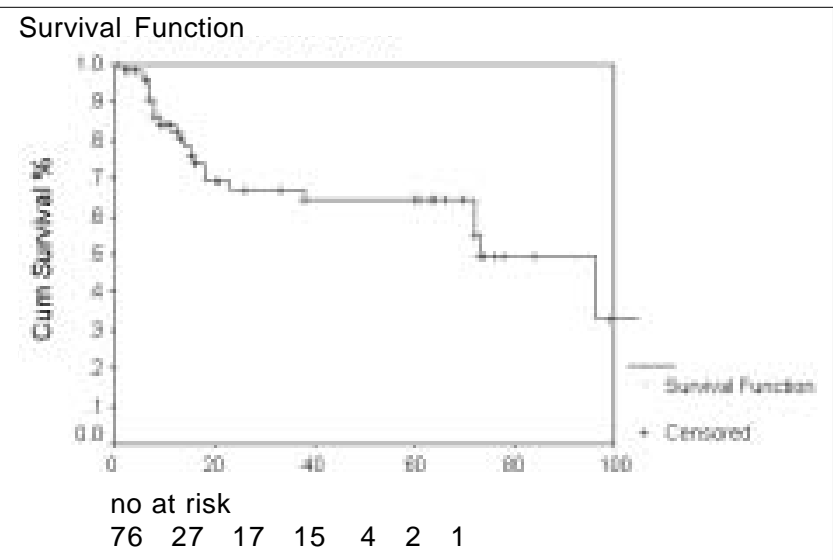

Figure 2: Overall survival in months

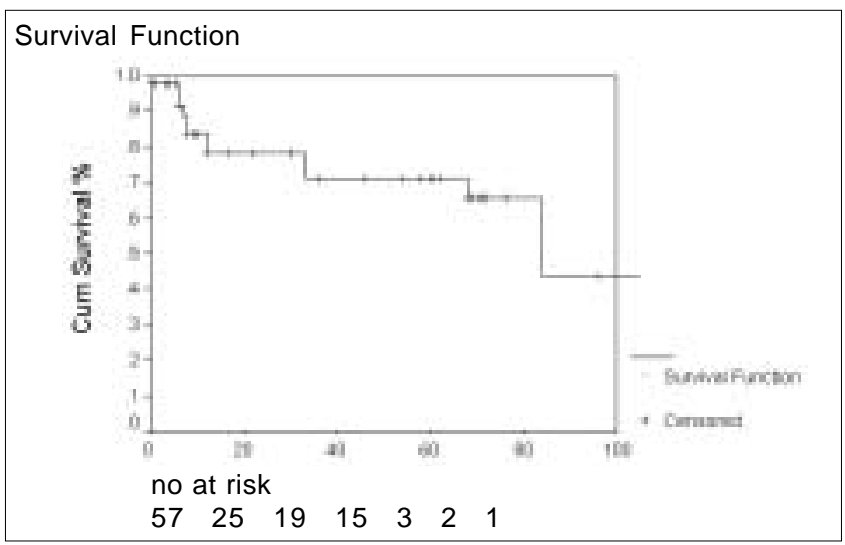

Figure 3: Evemt free survival in months

\section{Table 4: EFS and OS of various treatment groups}

\begin{tabular}{lccc}
\hline Type of treatment & N & $\begin{array}{c}\text { EFS } \\
\text { (60 months) }\end{array}$ & $\begin{array}{c}\text { OS } \\
\text { (60 months) }\end{array}$ \\
\hline Complete resection + CT & 21 & $60 \%$ & $64 \%$ \\
\hline Partial resection + CT & 23 & $62 \%$ & $60 \%$ \\
\hline Only chemotherapy & 33 & $68 \%$ & $67 \%$ \\
\hline All group & 77 & $72 \%$ & $65 \%$ \\
\hline
\end{tabular}

abdominal pain. ${ }^{[7]}$ In our series, $81 \%$ of patients had abdominal pain as presenting feature. More than half $(54.5 \%)$ of our patients had B symptoms, which is higher than Western data. ${ }^{[3,19-21]}$ We have noted equal distribution of gastric and intestinal lymphomas, Gastric: $46.7 \%$, Intestinal 53.3\%. [Table 5] summarizes anatomic location of the initial disease in the GI tract reported in recent studies..$^{[2,3,8,9,22,23]}$ In the majority of the studies, stomach is the commonest site of involvement. With the introduction of the entity MALT lymphoma by Issacson, more and more gastric MALT lymphomas are diagnosed. ${ }^{[24]}$ As reported in recent series by Peter et al, $40 \%$ of stomach NHL were of
Table 5: Sites of involvement in primary GI-NHL: different studies

\begin{tabular}{|c|c|c|}
\hline First author & $\begin{array}{l}\text { No. of } \\
\text { subjects }\end{array}$ & Distribution \\
\hline \multirow[t]{3}{*}{ Raina et al (Present study) } & 77 & 36 stomach \\
\hline & & 28 small intestine \\
\hline & & 13 large intestine \\
\hline \multirow[t]{4}{*}{ Peter Koch ${ }^{[3]}$} & 371 & 277 stomach \\
\hline & & 32 small intestinal \\
\hline & & 26 theocecal region \\
\hline & & 24 multiple sites \\
\hline \multirow[t]{3}{*}{ d'Amore $^{[2]}$} & 306 & 175 stomach \\
\hline & & 09 intestine \\
\hline & & 22 both \\
\hline \multirow[t]{2}{*}{ Radaskiewicz $^{[9]}$} & 307 & 244 stomach \\
\hline & & 63 intestine \\
\hline \multirow[t]{2}{*}{ Gurney $^{[22]}$} & 883 & 463 stomach \\
\hline & & 419 intestine \\
\hline \multirow[t]{2}{*}{ Liang $^{[23]}$} & 433 & 238 stomach \\
\hline & & 184 intestine \\
\hline \multirow[t]{2}{*}{ Morton $^{[8]}$} & 175 & 78 stomach \\
\hline & & 95 intestine \\
\hline
\end{tabular}

MALT type. ${ }^{[3]}$ In our series, there was no patient with MALT lymphoma.

Fifty two percent of our patients had disseminated disease at the time of diagnosis (stage $\mathrm{II}_{2} \mathrm{E}+$ stage IVE) in contrast to the Western reports of $10 \%$ $31 \% \cdot{ }^{[7,3]}$

Surgery with or without chemoradiotherapy has been the mainstay in the treatment of GI-NHL but this may be questioned. In a report by Brigitte et al $90 \%$ of cases underwent surgery followed by chemotherapy with $61 \%$ OS at 2 years. ${ }^{[6]}$ Two important large prospective studies have been reported recently. In German trial, of 371 patients with primary GI-NHL $44 \%$ had intermediate to high-grade lymphoma; received surgery + chemotherapy and had 5 year overall survival of $64 \% .{ }^{[3]}$ In a study on gastric lymphoma from Mexico 589 patients were randomized to either surgery $(S)$ with or without radiotherapy (SRT) and chemotherapy (SCT) and chemotherapy (CT) alone, actuarial curves at 10 years showed that overall survivals (OS) were: S: 54\%; SRT: 53\%; SCT: 91\%; CT: $96 \%(P<0.001)$. Late toxicity was more frequent and severe in patients who underwent surgery. ${ }^{[11]}$ We believe that advanced primary GI-NHL requires a systemic rather than a local approach and therefore we administered chemotherapy in all patients. Many of our patients underwent surgery (59\%) before coming to us and this gave us an opportunity to 
Table 6: Four large series of GI-NHL reported from India

\begin{tabular}{|c|c|c|c|c|}
\hline Features & $\begin{array}{c}\text { Raina } \\
\text { (present study) }\end{array}$ & $\begin{array}{c}\text { Ramesh Chandran } \\
\text { et } \mathrm{al}^{\left[{ }^{[4]}\right.}\end{array}$ & $\begin{array}{l}\text { Singh } \\
\text { et } \text { al }^{[25]}\end{array}$ & $\begin{array}{l}\text { Pandey } \\
\text { et } a^{[26]}\end{array}$ \\
\hline Median number (n) & 77 & 49 & 75 & 30 \\
\hline Age (yrs) & 32 & 30 & 34 (mean) & 40 (mean) \\
\hline M: F ratio & $2.2: 1$ & 2.8:1 & $1.9: 1$ & $1.2: 33$ \\
\hline B symptoms (\%) & 54.4 & 53 & 85 & 36.7 \\
\hline Predominant symptoms & Abdominal pain & Abdominal pain & Abdominal pain & Vomiting \\
\hline \multicolumn{5}{|l|}{ Stage wise distribution (\%) } \\
\hline IE & 16.5 & 28 & 36 & Not specific \\
\hline $\mathrm{II}_{1} \mathrm{E}$ & 20.3 & 37 & 40 & Not specific \\
\hline $\mathrm{II}_{2} \mathrm{E}$ & 36.7 & 20 & 14.7 (StagellI) & Not specific \\
\hline IV & 15.2 & 15 & 8 & Not specific \\
\hline Histopathology (\%) & Diffuse large cell & High grade & Diffuse histiocytic & \\
\hline \multirow[t]{2}{*}{ (commonest) } & (working) & lymphoblastic (working) & and diffuse poorly & Large cell \\
\hline & & \multicolumn{3}{|c|}{ differentiated (Rappaport's) } \\
\hline \multicolumn{5}{|l|}{ os } \\
\hline Stomach & $60 \%$ & $47 \%$ (all patients) & $44 \%$ & $73 \%$ \\
\hline SI & $69 \%$ & & $24 \%$ & $76 \%$ \\
\hline
\end{tabular}

compare the results in two groups. We had $67 \%$ survival at 5 years in patients receiving only chemotherapy as compared to $60-64 \%$ in surgery + CT arm (incomplete surgery, chemotherapy and complete surgery and chemotherapy respectively), which had borderline statistical significance $(P=0.05)$.

Presentation of GI-NHL in India is different from that in developed world. Different features of Indian studies are summarized in [Table 6]. All the studies reported from India are retrospective and have small number of patients. Survival with surgery and RT was reported to be $44 \%$ in stomach \& $24 \%$ in intestinal NHL which is lower than surgery and chemotherapy $(73 \%$ for stomach and $76 \%$ for intestinal type). ${ }^{[25,26]}$ Patients in the study by Chandran $e t$ al had OS of $47 \%$ at 5 years and the treatment modalities used were surgery $+\mathrm{RT}$, surgery $+\mathrm{CT}$, surgery $+\mathrm{CT}+\mathrm{RT}$ and $\mathrm{CT}+\mathrm{RT}$. ${ }^{[4]}$ OS in our study was $60 \%$ for stomach and $69 \%$ for intestinal type at 5 years.

This study questions the need for surgical intervention in diagnosis and treatment of GI-NHL except in emergency situations. There is a need to have prospective studies in this country by various centers to come out with definitive treatment guidelines.

\section{Conclusion}

Treatment of primary GI NHL is changing and chemotherapy alone is emerging as an attractive option. This has been brought about by: 1) advances in endoscopic diagnosis whereby a laparotomy is no longer necessary; 2) very high efficacy of chemotherapy; 3 ) studies showing that extensive resection may not be necessary with emphasis shifting to organ preservation and finally the concept that; 4) NHL being a systemic disease, a systemic approach like chemotherapy would be more appropriate. Our study indicates that results of chemotherapy alone are not inferior to resection with chemotherapy.

\section{References}

1. Devassa SS, Fears T. Non-Hodgkin's lymphoma time trends: United States and International Data. Cancer Res 1992;52:5432S40S.

2. d'Amore F, Christensen BE, Brincker H, Pedersen NT, Thorling K, Hastrup J, et al. Clinico-pathological features and prognostic factors in extranodal non-Hodgkin's lymphomas. Eur J Cancer 1991;27:1201-8.

3. Peter K, Francisco DV, Wolfgang EB, Normann AW, Berthold R, Wolfgang $\mathrm{H}$, et al. Primary Gastrointestinal Non-Hodgkin's lymphoma. Anatomic and histological distribution, clinical features and survival data of 371 patients registered in the 
German multicenter study. GIT NHL 01/92. J Clin Oncol 2001;19:3861-73.

4. Chandran R, Hemanth R, Harit KC. Primary Gastrointestinal Lymphoma: 30 years experience at the cancer institute, Madras, India. J Surg Oncol 1995;60:41-9.

5. Michael ML, Susan BW, Jan HW. Role of surgery in the management of primary lymphoma of the gastrointestinal tract. J Surg Oncol 1996;61:199-204.

6. Brigitte D, Peter NB, Thaddaus R. Primary gastrointestinal nonHodgkin's lymphoma. A retrospective clinicopathologic study of 150 cases. Cancer 1985;55:1060-73.

7. Loehr JW, Mujahed Z, Zahn FD, Gray GF, Thorbjarnarson B. Primary lymphoma of the gastrointestinal tract: A review of 100 cases. Ann Surg 1969; 170:232-8.

8. Morton JE, Leyland MJ, Vaughan HG, Vaughan HB, Anderson L, Bennett $\mathrm{MH}$, et al. Primary gastrointestinal non -Hodgkin's lymphoma. A review of 175 British National Lymphoma Investigation cases. Br J Cancer 1993;67:776-82.

9. Radaszkiewicz T, Dragosics B, Bauer P. Gastrointestinal malignant lymphomas of the mucosa associated lymphoid tissue. Factors relevant to prognosis. Gastroenterology 1992;102:1628-38.

10. Lee J, Kim WS, Kim K, Ko YH, Kim JJ, Kim YH, et al. Intestinal lymphoma; exploration of prognostic factors and optimal treatment. Leukemia Lymphoma 2004;45:339-44.

11. Aviles A, Nambo MJ, Neri N, Huerta GJ, Cuadra I, Alvarado I, et al. The role of surgery in gastric lymphoma, results of a controlled trial. Ann Surg 2004;240:44-50.

12. Schmidt w, Schmitz N, Sonnen R. Conservative management of Gastric Lymphoma: the treatment option of choice. Leukemia Lymphoma 2004;45;1847-52.

13. Binn M, Fourmestraux R, Lepage E, Haioun C, Delmer A, Aegerter $\mathrm{P}$, et al. Surgical resection plus chemotherapy versus chemotherapy alone comparison of two strategies to treat diffuses large B - cell gastric lymphoma. Ann Oncol 2003; 14:1751-7.

14. Lewin KJ, Ranchod M, Dorfman RF. Lymphomas of the gastrointestinal tract: A study of 117 cases presenting with gastrointestinal disease. Cancer 1978;42:693-707.

15. Musshoff K, Klinische Stadieneinteilung der Nicht-Hodgkin-
Lymphome. Strahlentherapie 1977; 153:218-21.

16. The Non-Hodgkin's Lymphoma pathologic classification Project:National Cancer Institute sponsored study of classifications of non-Hodgkin's lymphoma summary and description for clinical usage. Cancer 1982;49:2112-35.

17. Advani S, Pai S, Adde M, Vaidya S, Vats T, Naresh K, et al. preliminary report of an intensified, short duration chemotherapy protocol for the treatment of pediatric non-Hodgkins lymphoma in India. Ann Oncol 1997;8:893-7.

18. Cheson BD, Horning SJ, Coiffier B, Margaret AS, Richard IF, Joseph $\mathrm{MC}$, et al. Report of an international workshop to standardize response criteria for non- Hodgkins lymphomas. J Clin Oncol 1999 17; 1244-53.

19. John JB, Horatio TE. Primary gastric lymphomas. A clinicopathologic study of 58 cases with long term follow up and literature review. Cancer 1983;51:701-11.

20. Andres JMF, Stefano C, Serena P, Maurillo P, Massimo F, Fabrizio $\mathrm{V}$, et al. Therapeutic management of stage I-II high grade primary gastric lymphomas. Oncology 1999;56:274-82.

21. Cortelazzo S, Rossi A, Roggero F, Oldani E, Zucca E, Tondini C, et al. Stage modified international prognostic index effectively predicts clinical outcome of localized gastric diffuse large B-Cell lymphoma. Ann Oncol 1999; 10:1433-40.

22. Gurney KA, Cartwright RA, Gilman EA. Descriptive epidemiology of gastrointestinal Non-Hodgkin's lymphoma in a population based registry. Br J Cancer 1999;79:1929-34.

23. Liang R, Todd D, Chan TK, Chui E, Lie A, Kwong YL, et al. Prognostic factors for primary gastrointestinal lymphoma. Hematol Oncol 1995; 13:153-63.

24. Isaacson $P$, Wright $D H$. Extranodal malignant lymphoma arising from mucosa associated lymphoid tissue. Cancer 1984;53:2515-24.

25. Singh DP, Sharma SS, Sandhu AP, Goenka MK, Kochhar R, Nagi $\mathrm{B}$, et al. Primary gastrointestinal lymphoma - disease spectrum and management: A 15-year review from North India. Indian J Gastrointerol 1970;16:88-90.

26. Pandey M, Wadhwa MK, Patel HP, Kpthari KC, Shah M, Patel DD. Malignant lymphoma of the gastrointestinal tract. Eur J Surg Oncol 1999;25: 164-7. 